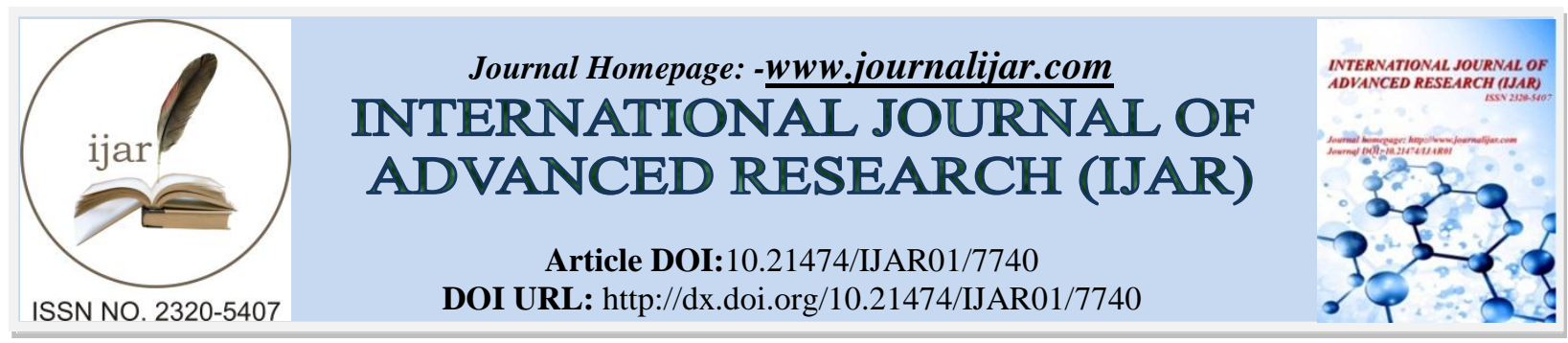

RESEARCH ARTICLE

\title{
ICD INSERTION AND MANAGEMENT IN PAEDIATRIC AGE GROUP- A CASE SERIES.
}

\section{Prof.Dr.G.Hariharan ${ }^{1}$, Prof.Dr.V.Gomathi ${ }^{1}$, Dr.A.Ajay Kumar ${ }^{2}$ and Dr.Varsha.M.Totadri' ${ }^{2}$}

1. M.Ch, Dept. Of Paediatric surgery, Govt. Stanley Medical College, Chennai.

2. Junior Resident, Dept of Paediatric Surgery Govt. Stanley Medical College, Chennai.

\section{Manuscript Info}

Manuscript History

Received: 23 July 2018

Final Accepted: 29 August 2018

Published: September 2018

Keywords:-

Pneumothorax,hemothorax,pyot horax.

\section{Abstract}

New born and paediatric age group thoracostomy/ICD insertion requirement is same as adult but intervention and timely management is different.OSLERIAN principles of observation inspection palpation and auscultation were followed in our series of patients.adequate ventilation were obtained symmetrical chest expansion were observed and auscultation of breath sounds bilaterally was done and the same was confirmed radiologically.normal ventilation and oxygenation were established and confirmed after ICD insertion.normal breath volume varies from 70 t0 $80 \mathrm{ml} / \mathrm{kg}$

Copy Right, IJAR, 2018,. All rights reserved.

\section{Introduction:-}

Intercostal drainage tubes allow draining of the pleural spaces of air, blood or fluid, allowing expansion of the lungs and restoration of negative pressure in the thoracic cavity. Appropriate chest drain management is required to maintain respiratory function and haemodynamic stability. Chest drains may be placed routinely in theatre, PICU and NICU; or in the emergency department and ward areas in emergency situations.

Haemothorax: Collection of blood in the pleural space

Pneumothorax: Collection of air in the pleural space

Indications for Insertion of a Chest Drain

1. Post operatively e.g. cardiac surgery, thoracotomy

2. Pneumothorax

3. Haemothorax

4. Chylothorax

5. Pleural effusions

Case discussion and series :

We present below cases that presented to us with pleural/lung pathologies and the appropriate management of the same basis evaluation of each child

\section{Case 1:}

A Newborn baby on DAY 1 of life presented with respiratory distress of unknown cause. Antenatal period in mother was uneventful. Baby was initiated on CPAP mode of ventilation due to persistent desaturation and tachypnea. In view of no improvement in condition, child was intubated and placed on mechanical ventilation.

Post intubation X-ray was taken and baby was identified to have developed pneumothorax- most probably due to mechanical ventilation associated barotrauma and excessive positive pressure ventilation. ICD insertion was done 
immediately on the side of pneumothorax. Baby was gradually weaned off mechanical ventilator support, only after which ICD was removed under sterile conditions after ensuring adequate lung expansion.

Conditions to rule out when a newborn has pneumothorax- barotrauma, posterior urethral valve

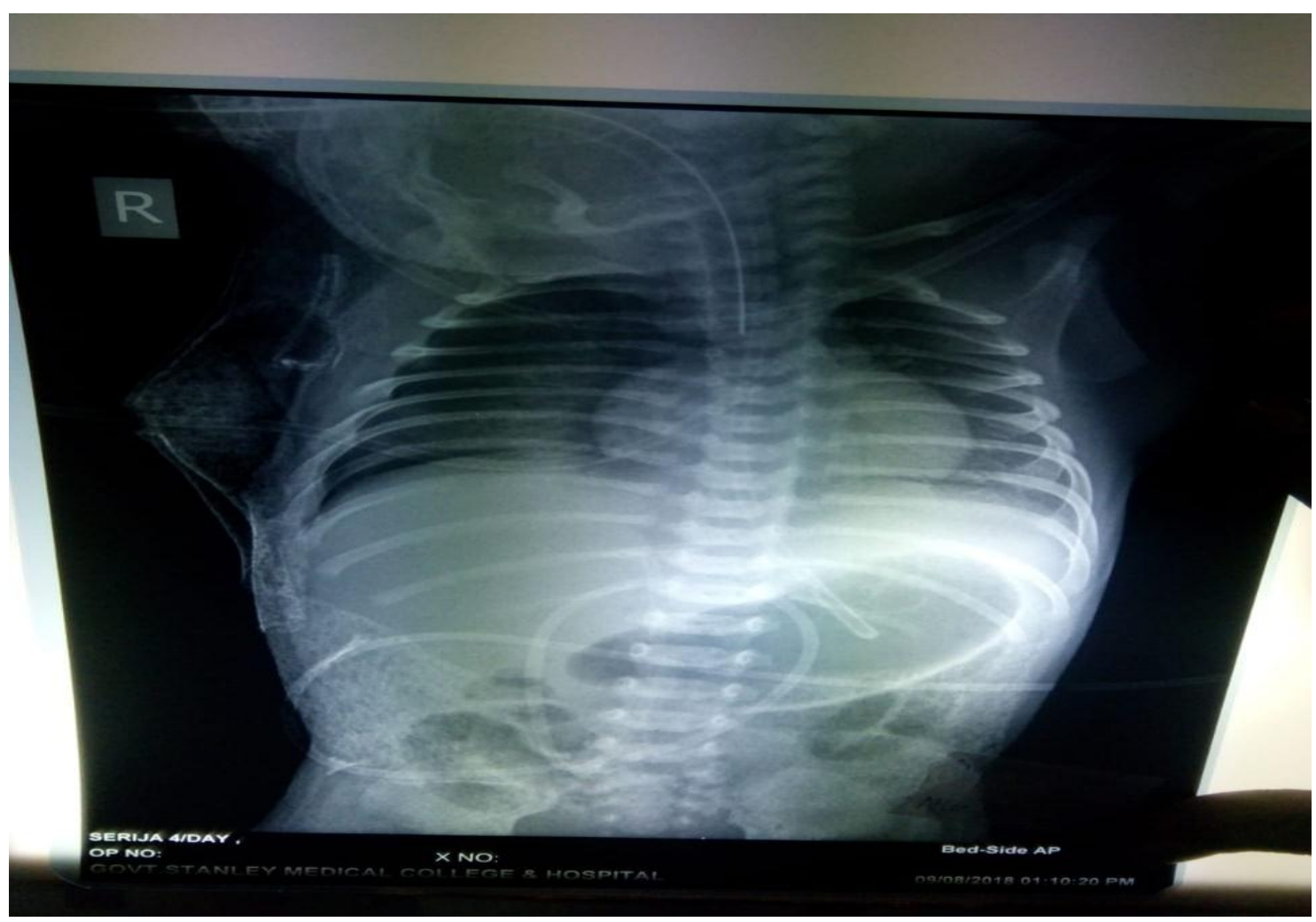

New born child with pneumothorax due to excessive cpap ventilation

\section{Case 2:}

A 12 year old girl presented with chief complaints of cough, breathlessness and intermittent fever since one month. Chest X ray was taken where there was evidence of right side pleural effusion. Diagnostic and therapeutic pleural tap was done and fluid sent for analysis which showed elevated LDH and proteins. Child again developed pleural effusion due to which ICD was inserted. On day 1 post ICD insertion a Chest X ray was repeated which showed persistence of a localized effusion in middle zone which was removed via a USG guided pleural aspiration. Nephrotic syndrome and dengue syndrome were ruled out. After pleural tapping, management with injectable Vancomycin and albumin was done. Chest medicine opinion was sought and ATT initiated. Child did not develop re effusion thereafter and after ensuring good lung expansion on repeat Chest X ray, ICD was removed on day 3. 


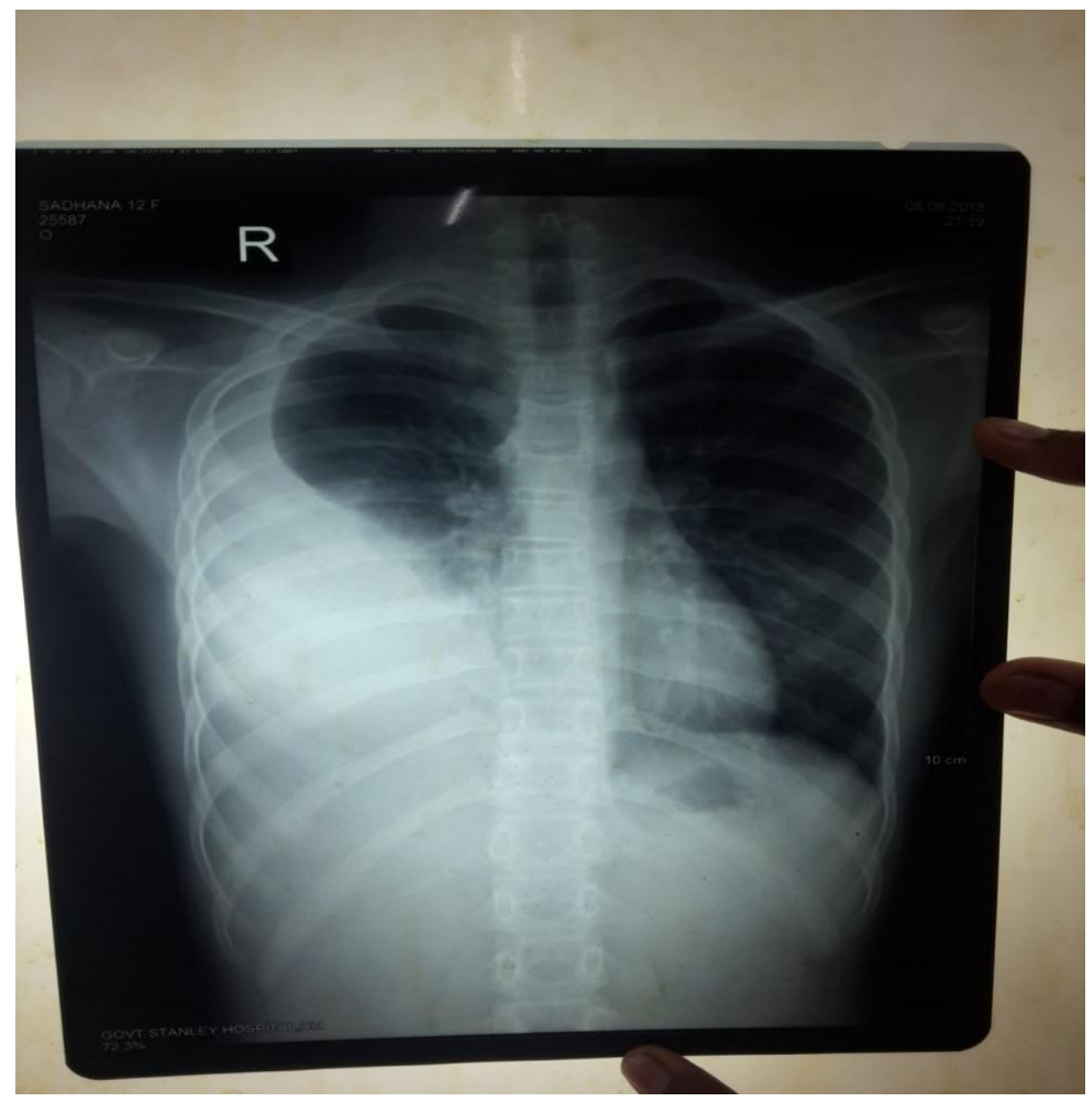

Right pleural effusion

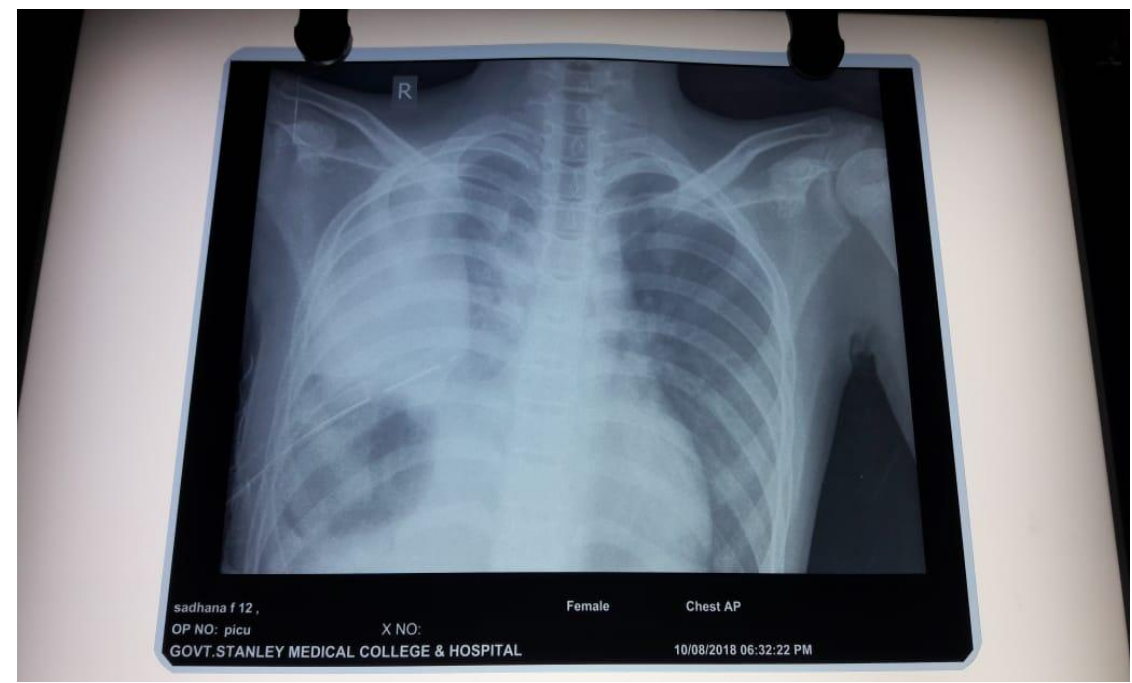

Post ICD insertion

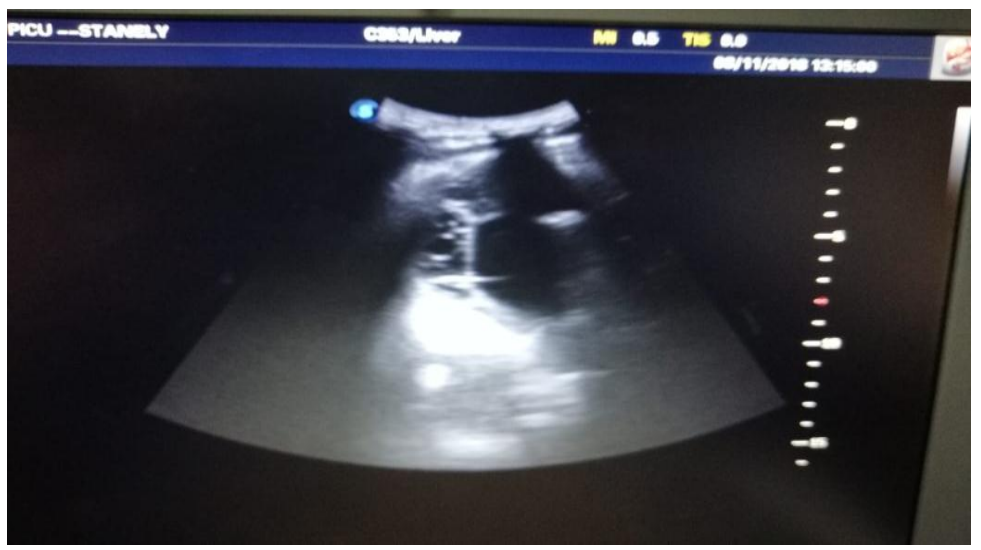

USD Guided tapping of pleural effusion

Case 3: 
A 6 yr old child presented with one month history of evening rise of temperature. Chest X ray was taken and was suspicious of pleural effusion following which CECT chest was taken which showed evidence of empyema. Videothoracoscopic drainage of empyema was done and pus sent for analysis which was suggestive of TB etiology. Child was started on ATT. 1 month later child came for review with complaints of intermittent episodes of fever of moderate grade with cough. Repeat CT chest showed recurrent empyema eventhough child was on regular ATT. Child was thereafter taken up for thoracotomy and decortication. Intraoperatively ICD was placed. Child had subcutaneous emphysema post operatively over right side of chest and abdomen. ICD was kept in situ till reduction in subcutaneous emphysema and till adequate lung expansion. ICD was thereafter removed on POD 6. Child was resumed on ATT from POD 1. Child thereafter clinically improved.

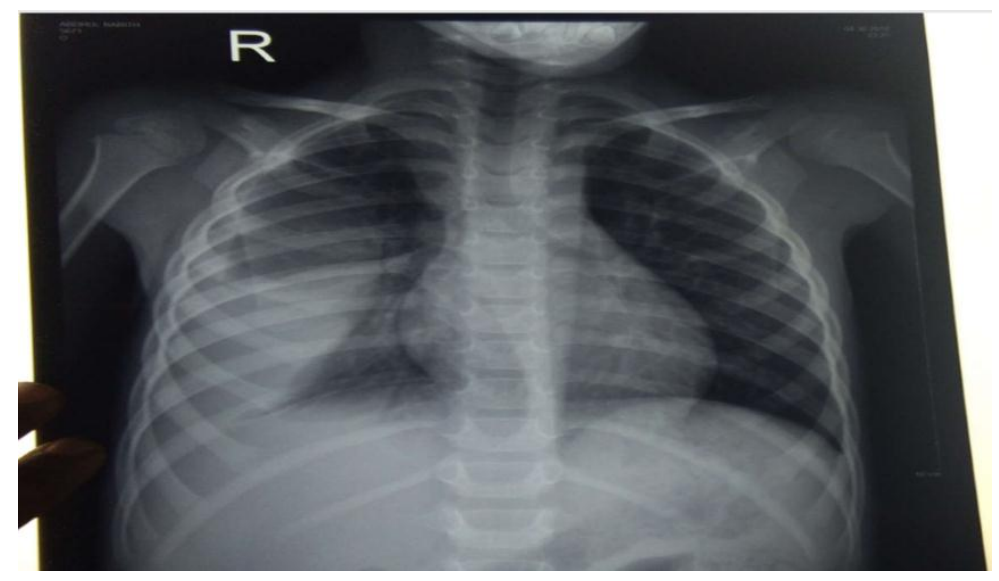

Pre Op Xray Chest
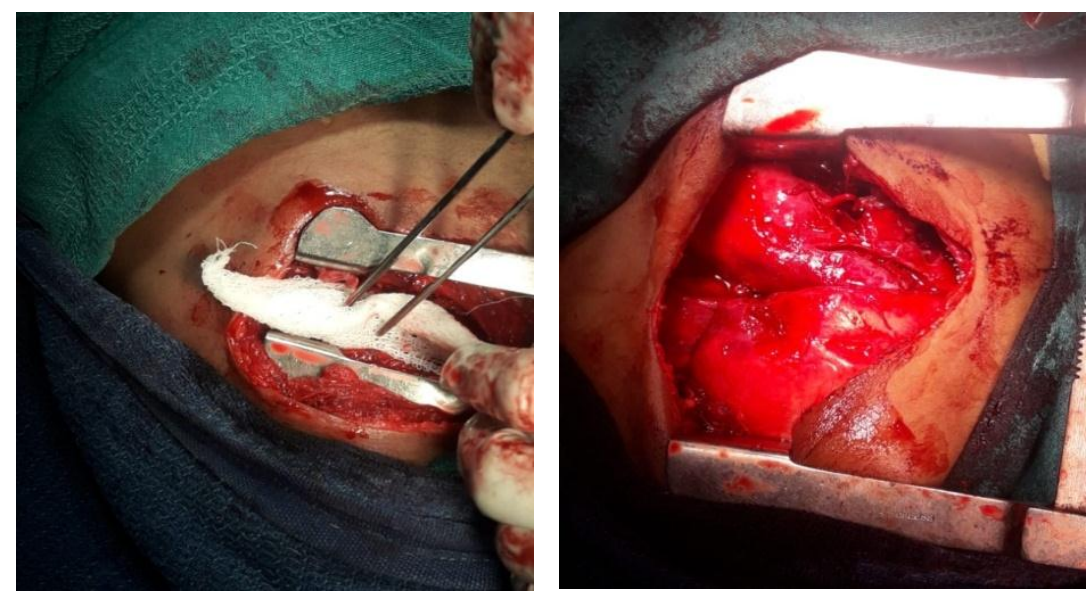

Decortication 


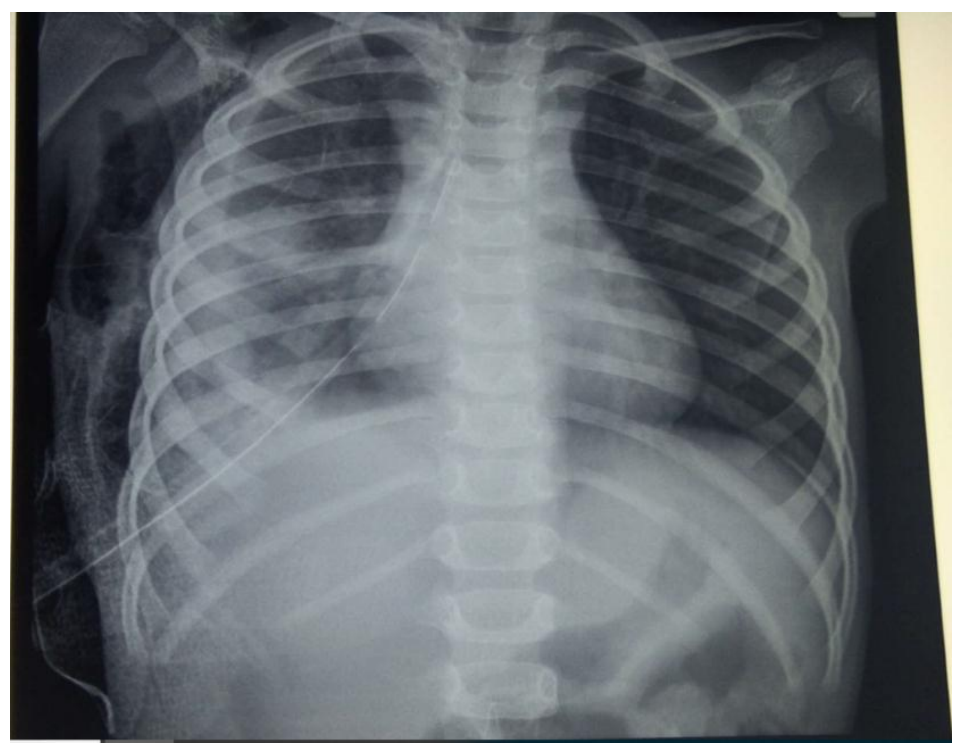

Post Decortication

\section{Conclusion:-}

Attaining proper ventilation and oxygenation during ventilator management for children should be carefully observed. OSLERIAN principles of observation inspection palpation and auscultation should be followed in our series of patients.adequate ventilation were obtained symmetrical chest expansion should be observed and auscultation of breath sounds bilaterally should be done and the same should be confirmed radiologically.

\section{References:-}

1. Playfair WS : on the treatment of empyema in children. obstec society of London trans $14.4,1872$

2. Graham EA, Bell RD :open pneumothorax :its reaction to the treatment of empyema. Am J Med sci 156:839, 1918

3. Luck SR,raffensperger JG,Sullivan HJ ,et al:management of pneumothorax in children with chronic pulmonary diseases.J thorac cardiovasc surg 1997;74;834

4. Knudtson J,grewel H ;paediatric empyema-an algorithm for early thoracoscopic intervention JSLS 2004;8:31

5. Sarihan H,Cay A ,Aynaci M ,et al: empyema in children.J Cardiovasc surg (torino) 1998;39:113. 